\title{
Improving the Stability of Red Blood Cells in Rainbow Trout (Oncorhynchus mykiss) and Herring (Clupea harengus): Potential Solutions for Post-mortem Fish Handling to Minimize Lipid Oxidation
}

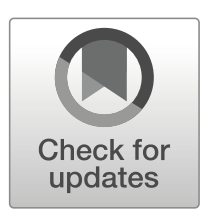

\author{
S. Ghirmai ${ }^{1}$ (D) $\cdot$ L. Eriksson $^{1} \cdot$ H. Wu ${ }^{1} \cdot$ M. Axelsson ${ }^{2} \cdot$ I. Undeland ${ }^{1}$
}

Received: 13 February 2020 / Accepted: 3 June 2020 / Published online: 22 June 2020

(C) The Author(s) 2020

\begin{abstract}
This study aimed at limiting hemolysis of fish red blood cells (RBCs) as a strategy to limit hemoglobin (Hb)-induced lipid oxidation during post-mortem handling and processing. Effects of varying temperature, salinity, and mechanical impact were studied using washed resuspended RBCs (wr-RBCs) and whole blood (WB) from rainbow trout (Oncorhynchus mykiss) and herring (Clupea harengus). The wr-RBCs were most stable avoiding mechanical stress, keeping isotonic conditions $(0.9-1.3 \%$ $\mathrm{NaCl}$ ) and low temperature $0-6{ }^{\circ} \mathrm{C}$, with predicted minimum at $2.5^{\circ} \mathrm{C}$. When compared at the same salinity, it was found that hemolysis was more pronounced in herring than trout wr-RBCs. Furthermore, WB was more stable than wr-RBCs, showing protecting the effects of blood plasma. Studying individual plasma components, stabilizing effects were found from glucose, proteins, and ascorbic acid. This study indicates that small adjustments in the early handling and processing of fish such as changing salinity of storage and rinsing solutions could minimize $\mathrm{Hb}$ contamination of the fish muscle and thereby improve quality.
\end{abstract}

Keywords Fish $\cdot$ Hemoglobin $\cdot$ Hemolysis $\cdot$ Erythrocyte $\cdot$ Blood plasma components $\cdot$ Lipid oxidation

Electronic supplementary material The online version of this article (https://doi.org/10.1007/s11947-020-02472-3) contains supplementary material, which is available to authorized users.

S. Ghirmai

semhar.ghirmai@chalmers.se

L. Eriksson

erikssonlinneam@gmail.com

H. Wu

haizhou@chalmers.se

M. Axelsson

michael.axelsson@bioenv.gu.se

I. Undeland

undeland@chalmers.se

1 Department of Biology and Biological Engineering -Food and Nutrition Science, Chalmers University of Technology, Kemigården 4, SE-412 96 Gothenburg, Sweden

2 Department of Biological and Environmental Sciences, Gothenburg University, Medicinaregatan 18A, SE-413 90 Gothenburg, Sweden

\author{
Abbreviations \\ BSA Bovine serum albumin \\ $\mathrm{Hb} \quad$ Hemoglobin \\ Hct Hematocrit \\ metHb Methemoglobin \\ PEST Penicillin-streptomycin \\ PUFA Polyunsaturated fatty acid \\ RBC Red blood cell \\ RSW Refrigerated seawater \\ WB Whole blood \\ wr-RBC Washed resuspended red blood cells
}

\section{Introduction}

Post-mortem, fish muscle is highly susceptible to lipid oxidation due to its abundance of polyunsaturated fatty acids (PUFAs) and, in some cases, blood, the latter containing the strong pro-oxidant hemoglobin ( $\mathrm{Hb}$ ) (Larsson et al. 2007; Li et al. 2005; Richards and Hultin 2002; Undeland and Lingnert 1999). Lipid oxidation gives rise to unwanted flavor, 
pigmentation, textural changes, and nutritional loss (Cavonius and Undeland 2017; Larsson and Undeland 2010; Maqsood and Benjakul 2011; Richards and Hultin 2002; Undeland et al. 2004; Undeland and Lingnert 1999), causing underutilization of particularly small pelagic dark muscle fish species for human consumption. Large fractions of, e.g., herring, sardines, and anchovy caught globally are instead converted into lowvalue products such as feed for fur animals or fish meal and fish oil for aquafeed production. Similarly, by-products from the filleting industry are highly susceptible to lipid oxidation due to richness in both blood and PUFAs (Wu et al. 2020). This renders food production from by-products difficult, despite their large amounts of high-quality muscle.

As the pro-oxidative nature of fish $\mathrm{Hb}$ is well established (Larsson et al. 2007; Li et al. 2005; Richards and Hultin 2002; Undeland et al. 2003), several routes have been developed in the past decades to prevent $\mathrm{Hb}$-mediated lipid oxidation in fish, aiming at maintaining $\mathrm{Hb}$ in its reduced form or at scavenging lipid- or Hb-derived radicals by adding specific antioxidants or antioxidant containing extracts from, e.g., plants and algae (Babakhani et al. 2016; Li et al. 2016; Lu et al. 2014; Maqsood and Benjakul 2013; Miranda et al. 2018; Sánchez-Alonso et al. 2007; Wang et al. 2010). Other common strategies to reduce Hbmediated lipid oxidation include bleeding the fish immediately after capture and applying rinsing with tap water during the filleting process to ensure maximal bleed out (Olsen et al. 2014; Roth et al. 2009). The practice of bleeding is however not applicable or economically feasible in commercial vessels targeting small pelagic fish species, as such fish is captured in large hauls, and bleeding has to be performed within minutes to ensure efficient removal of the blood (Olsen et al. 2014).

In a study conducted by Richards and Hultin (2002), preliminary evidence emerged that minimizing hemolysis of red blood cells (RBCs) could minimize lipid oxidation of washed cod muscle mince. They also found that the full lipid prooxidative capacity of whole blood was accounted for the soluble content of RBCs, with $\mathrm{Hb}$ playing a profound role. Similarly, Perez et al. (2019) reported that lysed RBCs promoted faster lipid oxidation in washed turkey muscle compared with intact RBCs. Based on these findings, we hypothesize that several process parameters typical to the fishing and fish processing industry negatively affect the fish RBC stability and would therefore stimulate lipid oxidation development. In steps with liquid involved, perhaps the most obvious process parameter expected to affect the stability of RBCs is the salinity of surrounding media (Singh et al. 2019; Waymouth 1970). Scattered studies have explored the osmotic fragility of fish RBCs (Ezell et al. 1969; Fyhn et al. 1979; Khan et al. 1972; Lewis and Ferguson 1966), but no previous publications report on how osmotic pressure in a range of relevance for the seafood industry affects the stability of fish RBCs. For example, during storage of whole fish in refrigerated seawater (RSW) or common ice on the fishing vessel, the RBCs are exposed to hypertonic $(\sim 3 \% \mathrm{NaCl}, 513 \mathrm{mM})$ or hypotonic $(\sim 0 \% \mathrm{NaCl})$ conditions, respectively, trough the gills or wounds on the fish (Grahm et al. 1992; Huss 1995). In addition, the mentioned tap water $(0 \% \mathrm{NaCl})$ rinsing applied during the filleting would also subject residual RBCs to hypotonic conditions. Similarly, high osmotic pressure could appear, e.g., in pre-salting and marinating steps which comprise salt solutions from om $3 \%$ up to saturation. Other factors which could be critical to RBCs would be the mechanical stress which appears, e.g., during transport and sorting of fish, as well as temperature fluctuations (Blaine et al. 2019). Although the temperature is normally close to $0^{\circ} \mathrm{C}$ early in the process chain (Grahm et al. 1992; Huss 1995), it can raise, e.g., in filleting and washing steps and in the handling of by-products (Kuhlin 2019). The latter are often stored in outdoor temperature without any active cooling or antimicrobial protection which can induce the formation of, e.g., hemolysins (Vesper and Vesper 2004). Any step with liquid involved also implies a general dilution of the blood which can cause a shortage of nutrients and antioxidants (e.g., ascorbic acid), required for normal RBC function and integrity (B. Frei et al. (1989).

Altogether, there is thus a range of parameters which directly, or after prolonged storage, could induce lysis of fish RBCs. To the best of our knowledge, such parameters have however not before been systematically investigated. The aim of this study was to unravel how variations in salinity, mechanical impact, and temperature affect trout and herring RBC stability, thereby identifying the conditions that could maintain as much as possible of the $\mathrm{Hb}$ in its natural "encapsulated state" to prevent $\mathrm{Hb}$ contamination of the fish muscle and subsequent lipid oxidation. The results could ultimately lead to new routes to control seafood quality.

\section{Material and Methods}

\section{Fish Supply}

Rainbow trout (Oncorhynchus mykiss) was obtained from Antens laxodling $\mathrm{AB}$, Alingsås, Sweden. The fish was maintained in tanks with aerated freshwater, $\sim 10^{\circ} \mathrm{C}$, at Gothenburg University, Department of Biological and Environmental Sciences, Zoophysiology. The fish was kept under a 12:12 photoperiod and fed commercially available trout pellets. Live herring (Clupea harengus) was obtained from a commercial fishing boat at the southern west coast of Sweden, outside Helsingborg.

\section{Bleeding Procedure}

The bleeding of trout and herring was approved by the regional animal ethics committee in Gothenburg, permit number 1672013. Both fish species were killed by a blow to the head, and then, the blood was withdrawn from the caudal vessels with heparinized syringes (Heparin $5000 \mathrm{IU} / \mathrm{mL}$; LEO Pharma AB, 
Malmö, Sweden) and an additional $50 \mathrm{IU}$ heparin $/ \mathrm{mL}$ withdrawn blood was added. The blood was stored on an asymmetric blood mixer (Sarstedt AB, SARMIX® GM 1; Helsingborg, Sweden) in a cold room, $3( \pm 1)^{\circ} \mathrm{C}$ and used within $24 \mathrm{~h}$ after blood sampling. Hematocrit (hct) percentage was determined by sampling blood in sodium heparinized capillaries (Paul Marienfeld $\mathrm{GmbH}$ \& Co.KG; Lauda-Königshofen, Germany) and centrifuged at $15,000 \mathrm{rpm}$ for $2 \mathrm{~min}$ (Thermo Scientific ${ }^{\mathrm{TM}}$, Heraeus ${ }^{\mathrm{TM}}$ Fresco $^{\text {TM }} 17$ Microcentrifuge; Massachusetts, U.S.A.). The hct-\% was later used to calculate the volume of red blood cells (RBCs) to be transferred for the different storing solutions.

\section{Preparation of Washed Resuspended Red Blood Cells}

The whole blood (WB) was centrifuged (Thermo Scientific ${ }^{\mathrm{TM}}$ Heraeus ${ }^{\circledR}$ Multifuge ${ }^{\circ} 1$ centrifuge; Massachusetts, U.S.A.) at $700 \mathrm{~g}$ for $10 \mathrm{~min}$ at $4^{\circ} \mathrm{C}$ to collect the blood plasma. The RBCs were then washed three times according to a modified protocol by Fyhn et al. (1979) in which the 1.7\% (290 mM) NaCl was replaced by $0.9 \%(154 \mathrm{mM}) \mathrm{NaCl}$ to further prevent the $\mathrm{RBCs}$ from harm due to osmotic pressure. After the last wash, the supernatant was removed and the RBCs distributed to 5 -mL polypropylene tubes. The blood volume for each treatment was predetermined to $400 \mu \mathrm{L}$; thus, the amount of washed RBCs transferred was calculated based on the hct-\% measured on the WB. Based on original WB volume, the washed RBCs were diluted fivefold with the specific treatment and incubated on an SARMIX $®$ blood mixer in a cold room, $3( \pm 1){ }^{\circ} \mathrm{C}$, while measuring lysis of washed resuspended RBCs (wr-RBCs) over time. To ensure that washed RBCs were not damaged by the mechanical stress applied during the actual washing procedure, washed RBCs were resuspended in plasma and the stability towards hemolysis was compared with that of WB; no differences in hemolysis rate could be detected between these two samples.

\section{Preparation of Methemoglobin}

Methemoglobin (metHb) was prepared according to Lee et al. (2015). The millimolar extinction coefficient of $153 \mathrm{mM}^{-1}$ $\mathrm{cm}^{-1}$ at $405 \mathrm{~nm}$ was used to quantify metHb on a heme basis (Benesch et al. 1964). The absorbance was analyzed using a UV-Vis spectrophotometer (Agilent Technologies Cary 60 UV-Vis, California, U.S.A.).

\section{Effects of Osmotic Pressure, Temperature, and Mechanical Stress RBC Stability-Univariate Approach}

The osmotic fragility was investigated by diluting the washed $\mathrm{RBCs} / \mathrm{WB}$ in different salinities ranging from $0 \%(0 \mathrm{mM})$ up to $3 \%(513 \mathrm{mM}) \mathrm{NaCl}$, including salinities around the osmolality measured in trout and herring blood plasma (see
Analysis of Blood Plasma Components). Experiments conducted on trout WB consisted of pooled blood from three fish and were repeated 2-9 times. Hemolysis (see Measurement of Hemolysis) was then measured in duplicates or triplicates in each sample during storage up to 42 or 53 days for wr-RBCs and WB respectively. Experiments on herring blood were conducted on pooled blood from 11 and 17 fish $(n=2)$. Hemolysis (see Measurement of Hemolysis) was then measured in replicates $(r=2)$ in each sample during storage for up to 20 days. Effect of temperature was investigated by incubating trout wr-RBCs or WB in $0.9 \%(154 \mathrm{mM}) \mathrm{NaCl}$ at different temperatures: $0{ }^{\circ} \mathrm{C}$ (on ice), $4-6{ }^{\circ} \mathrm{C}$, or $10-12{ }^{\circ} \mathrm{C}$ (in temperature-controlled refrigerators). To study the effect of mechanical impact, wr-RBCs or WB was incubated in $0.9 \%$ $(154 \mathrm{mM}) \mathrm{NaCl}$ in polyethylene tubes at $4-6{ }^{\circ} \mathrm{C}$; the tubes were then dropped two or five times from $2 \mathrm{~m}$ high. The experiments designed to investigate temperature and mechanical stress were performed with two different batches of trout blood ( $n=2$ ), each batch consisting of pooled blood from three fish. Hemolysis (see Measurement of Hemolysis) was then measured in triplicates $(r=3)$ in each sample during storage up to 16 days for wr-RBCs and WB respectively.

\section{Effects of Osmotic Pressure, Temperature, and Mechanical Stress on RBC Stability-Multivariate Approach}

Interaction, linear, or/and quadratic effects between the study parameters salinity, temperature, and mechanical impact were investigated in a Box-Behnken design with three center points (see Supplement Information). Three levels were used for each of the parameters: (i) salinity: $120 \mathrm{mM}(0.7 \%)$, $145 \mathrm{mM}(0.85 \%)$, or $171 \mathrm{mM}(1.0 \%) \mathrm{NaCl}$; (ii) mechanical stress: no drop, drop from $2 \mathrm{~m}$ high, two times or five times; and (iii) temperature: $0{ }^{\circ} \mathrm{C}, 5( \pm 1){ }^{\circ} \mathrm{C}$, or $11( \pm 1){ }^{\circ} \mathrm{C}$. The experiments were performed with two different batches $(n=$ 2) of trout blood, each batch consisting of pooled blood from three trout. Hemolysis (see Measurement of Hemolysis) was then measured in triplicate $(r=3)$ in each sample at seven different time points: before mechanical stress $(0 \mathrm{~h})$, after mechanical stress $(0.5 \mathrm{~h})$, and after $3,5,7,11$, and 13 days of incubation, at the specific temperature and salinity. Hemolysis is $\log 10$ transformed in the graphs visualizing linear and quadratic effects of mechanical stress and temperature on hemolysis.

\section{Effects of Individual Plasma Components, Antimicrobial Agents, $\mathrm{KCl}$, and metHb on Hemolysis}

Plasma glucose concentration was measured to $6.0 \pm 0.4$ and $6.0 \pm 0.3 \mathrm{mM}(n=1, r=3)$, respectively, in trout and herring blood plasma (see Analysis of Blood Plasma Components). Endogenous ascorbic acid level found in trout plasma was 
$169.8 \pm 19.9 \mu \mathrm{M}(n=3, r=3)$ and in herring plasma $109.6 \pm$ $26.7 \mu \mathrm{M}(n=3, r=3$ ) (see Analysis of Blood Plasma Components). To evaluate concentrations both below and above the endogenous ones, 2, 6, 10, or $20 \mathrm{mM}$ glucose (Sigma-Aldrich) and 50, 100, or $200 \mu \mathrm{M}$ ascorbic acid (Sigma-Aldrich) were therefore added to herring and/or trout wr-RBCs in $0.9 \%(154 \mathrm{mM}) \mathrm{NaCl}$. MetHb (10 g/L) (see Preparation of Methemoglobin) was added based on the $\mathrm{Hb}$ released at the start of the exponential hemolysis phase and bovine serum albumin (BSA, $10 \mathrm{~g} / \mathrm{L}$ ) was added (SigmaAldrich) in the same concentration as metHb to compare the effect of an other globular protein. Hemolysis was analyzed as described in the "Statistical Evaluations" section. Also, 100 $\mu \mathrm{g} / \mathrm{mL}$ streptomycin/penicillin-streptomycin (PEST) (SigmaAldrich) was tested for its antimicrobial effects. In all experiments, above wr-RBCs were suspended in 0.9\% (154 mM) $\mathrm{NaCl}$. However, also resuspension in $0.9 \%(154 \mathrm{mM}) \mathrm{KCl}$ and a mixture of $0.45 \%(77 \mathrm{mM}) \mathrm{KCl}$ and $0.45 \%(77 \mathrm{mM})$ $\mathrm{NaCl}$ was evaluated. All samples were stored at $3 \pm 1{ }^{\circ} \mathrm{C}$ for up to 42 days to evaluate the ability of these compounds to increase RBC stability.

\section{Analysis of Blood Plasma Components}

Trout and herring blood plasma osmolality was measured using an osmometer (Advanced ${ }^{\circledR}$ Instruments Inc., Microosmometer model 3320; Massachusetts, U.S.A.) and the results were later translated into $\mathrm{NaCl}$ equivalents in millimolar. The osmolarity of trout blood plasma as measured in three blood batches $(n=3)$ with three replicates $(r=3) 0.9 \pm$ $0.001 \%(152.0 \pm 1.2 \mathrm{mM})$. Osmolality in herring plasma as measured in one batch $(n=1)$ with four replicate measurements $(r=4)$ was found to be $1.1 \pm 0.001 \%(195.0 \pm 1.3 \mathrm{mM})$.

The glucose concentration of herring and trout plasma was measured using an enzyme-based glucose assay (Glucose (HK) assay kit; Sigma-Aldrich) where after spectra at $340 \mathrm{~nm}$ was measured in a microplate reader (SpectraMax 190 microplate reader, Fisher Scientific, U.S.A.). A blood batch $(n=1)$ was analyzed in triplicates $(r=3)$. Plasma ascorbic acid was measured in two batches of blood with three replicates $(n=2, r=3)$ using a modified version of the method described by Lykkesfeldt (Lykkesfeldt 2000). Upon use, the blood plasma sample was thawed, vortexed, sonicated $5 \mathrm{~min} \times 2$, and centrifuged at $16,000 \mathrm{~g}, 4^{\circ} \mathrm{C}$, and $2 \mathrm{~min}$. The supernatant was then centrifuged a second time with the same settings and then let to react for $15 \mathrm{~min}$ at room temperature with reaction buffer $(1: 1)$. The reaction buffer consisted of $0.312 \mathrm{mM}$ tris(2-carboxyethyl)phosphine (TCEP) (Honeywell Fluka) in (9:1) mobile phase $(50 \mathrm{mM}$ phosphate buffer, pH 2.8) and Mcllvaine buffer (0.46 M sodium phosphate dibasic and $0.27 \mathrm{M}$ citric acid, $\mathrm{pH} 4.5$ ). Further dilutions before measurement in the HPLC were made with dilution buffer: (9:1) mobile phase mixed with Mcllvaine buffer. For analysis, an HPLC (Jasco PU-2080Plus) coupled with an electrochemical detector (Decade II electrochemical detector, Antec Leyden, Netherlands) was used. The mobile phase consisted of $50 \mathrm{mM}$ phosphate buffer $\mathrm{pH} 2.8$ and the sample injection volume was $10 \mu \mathrm{L}$. The flow rate was set to $0.4 \mathrm{~mL} /$ min and the electrochemical detection in the glassy carbon flow cell was set to $0.60 \mathrm{~V}$ (DC mode, range $50 \mathrm{nA}$ ).

\section{Measurement of Hemolysis}

The stability of the RBCs was determined through the measurement of $\mathrm{Hb}$ in the supernatant, following centrifugation of a sub-sample $(100 \mu \mathrm{L})$ at $700 \mathrm{~g}$ at $4{ }^{\circ} \mathrm{C}$ for $10 \mathrm{~min}$. The supernatant was allowed to reach room temperature before measurement with a HemoCue $₫$ Plasma/Low (HemoCue $®$, HemoCue ${ }^{\circ}$ Plasma/Low Hb System; Ängelholm, Sweden. The total $\mathrm{Hb}$ of each wr-RBC/WB batch used in the study was estimated by preparing a hemolyzed sample according to the method by Fyhn et al. (1979). Hemolysis was expressed as the amount of $\mathrm{Hb}$ in the supernatant divided by the total $\mathrm{Hb}$ in the wr-RBC/WB used.

\section{Statistical Evaluations}

For experiments repeated two times or more (i.e., $n \geq 2$ ), the standard deviation (SD) is calculated and visualized as error bars and one-way analysis of variance (ANOVA) was conducted to determine statistical significance between different storage conditions. Tukey's post hoc test was conducted for a pairwise comparison when a significant effect was found, with a threshold of $p<0.05$. In cases where a representative graph from a series of experiments is visualized, SD is calculated based on the 3 repeated subsamples taken from each sample type $(r=3)$. Multivariate analysis of the data from the Behnken design was performed using a regression model with quadratic terms to assess the relation of hemolysis to temperature, salinity, and mechanical stress. Two-way ANOVA was performed on these factors to study the significance of each factor, with a threshold of $p<0.005$. All analysis was performed in R-studio version 3.5.1 (Team, R. C. 2019).

\section{Results}

\section{Effect of Salinity, Temperature, and Mechanic Stress on Hemolysis}

As illustrated in Fig. $1 \mathrm{a}$ and b, wr-RBCs or WB in $0 \% \mathrm{NaCl}$ resulted in instant hemolysis within $1 \mathrm{~h}$ of incubation. The wr$\mathrm{RBCs}$ or $\mathrm{WB}$ in $3 \%(513 \mathrm{mM}) \mathrm{NaCl}$ gave the second-fastest hemolysis, with $50 \%$ hemolysis $\left(\mathrm{T}_{50}\right)$ after around 3 and 6 days, for wr-RBCs and WB respectively. Both wr-RBCs and WB incubated in physiological salt concentration, $0.9 \%(154 \mathrm{mM})$ 
Fig. 1 Representative graphs of hemolysis of rainbow trout $\mathrm{RBCs}$ over time. Each point represents mean values \pm standard deviation, $\mathrm{SD}(r=3)$ for one blood batch. In graphs $\mathbf{a}, \mathbf{c}$, and $\mathbf{e}$, wr-RBCs are shown, whereas graphs $\mathbf{b}, \mathbf{d}$, and $\mathbf{f}$ show data from WB. Panels a and b visualize the effect of osmotic pressure on RBCs using $0 \%(0$ $\mathrm{mM}), 0.9 \%(154 \mathrm{mM})$, and $3 \%$ $\mathrm{NaCl}(513 \mathrm{mM})$. The dashdouble-dotted line (graph a), mark when $50 \%$ hemolysis was reached $\left(\mathrm{T}_{50}\right)$. Panels $\mathbf{c}$ and $\mathbf{d}$ show the effect of temperature $\left(0{ }^{\circ} \mathrm{C}, 4-6{ }^{\circ} \mathrm{C}\right.$ and $\left.10-12{ }^{\circ} \mathrm{C}\right)$ when samples are incubated in $0.9 \%$ $\mathrm{NaCl}$. Panels e and $\mathbf{f}$ show the impact of two different levels of mechanical stress (dropped 2 times from $2 \mathrm{~m}$ height and dropped 5 times from $2 \mathrm{~m}$ height) on hemolysis in comparison to the control
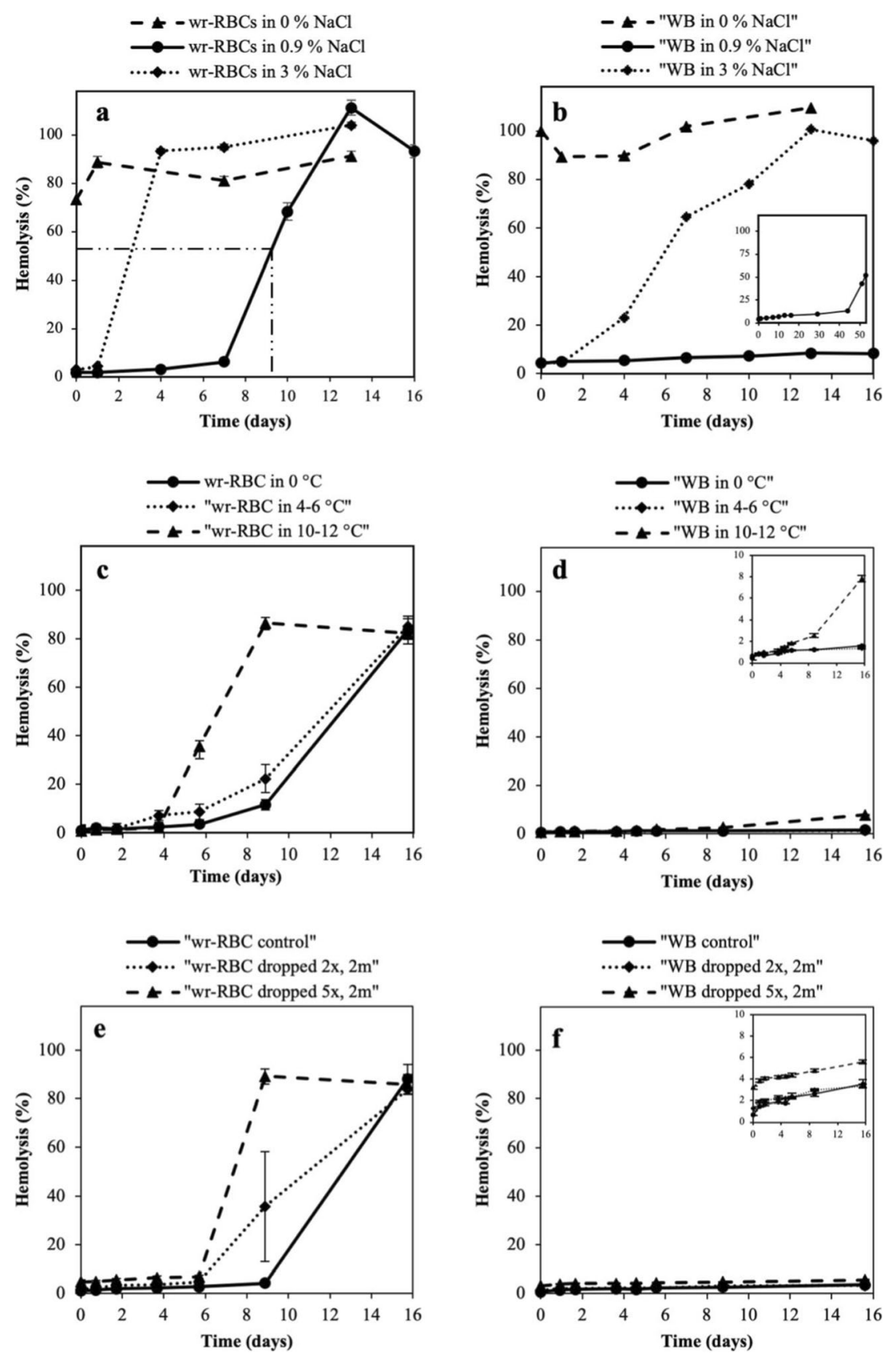

$\mathrm{NaCl}$, had the slowest hemolysis and reached $\mathrm{T}_{50}$ after 9 and 53 days, respectively. Results with $0.9 \% \mathrm{NaCl}$ were significantly different $(p<0.001)$ from those obtained in wr-RBCs with $3 \%$ $\mathrm{NaCl}$ at 4 and 7 days and from $\mathrm{WB}$ in $3 \% \mathrm{NaCl}$ during the whole time span. There was slight variability in the time required to reach $T_{50}$ between experimental repetitions, which was presumably due to biological variations between blood batches. However, the different salinities tested showed consistency in the order they caused hemolysis. No significant difference in hemolysis could be found between samples stored at 0 ${ }^{\circ} \mathrm{C}$ or $4-6{ }^{\circ} \mathrm{C}$ at the most protective salt concentration $0.9 \%$
(154 mM) $\mathrm{NaCl}$ (Fig. $1 \mathrm{c}$ and d). However, at the higher temperature, $10-12{ }^{\circ} \mathrm{C}$, a significantly higher level of hemolysis was found $(p<0.01)$ at days $6-9$ and days 6-16 for wr-RBCs and $\mathrm{WB}$ respectively, compared with the lower temperature range $0-6{ }^{\circ} \mathrm{C}$. Samples subjected to mechanical impact prior to storage in $0.9 \%(154 \mathrm{mM}) \mathrm{NaCl}$ (Fig. $1 \mathrm{e}-\mathrm{f})$, resulted in significantly $(p<0.01)$ faster hemolysis in both wr-RBCs and WB, only when the highest mechanical impact (5 drops from 2 $\mathrm{m}$ high) was applied. Furthermore, in all treatments (Fig. $1 \mathrm{a}-\mathrm{f}$ ), a lower degree of hemolysis was found in WB, i.e., when plasma was present, compared with wr-RBCs. 
Fig. 2 Days until trout and herring wr-RBCs reached $50 \%$ hemolysis $\left(\mathrm{T}_{50}\right)$ in samples with different salt concentrations, ranging from $0 \% \mathrm{NaCl}(0 \mathrm{mM})$ to $3.0 \% \mathrm{NaCl}(513 \mathrm{mM})$. Data are shown as the mean value $\pm \mathrm{SD}$ for all experiments. Experimental replicates for rainbow trout wrRBCs were as follows: $0 \%$ and $3 \% \mathrm{NaCl}(n=2) ; 0.7 \%, 1.1 \%$, $1.3 \%$, and $1.7 \% \mathrm{NaCl}(n=4)$; $0.9 \% \mathrm{NaCl}(n=9)$. All experiments for herring were repeated twice $(n=2)$ and all measurements for herring and trout were done in duplicates $(r=$ 2)

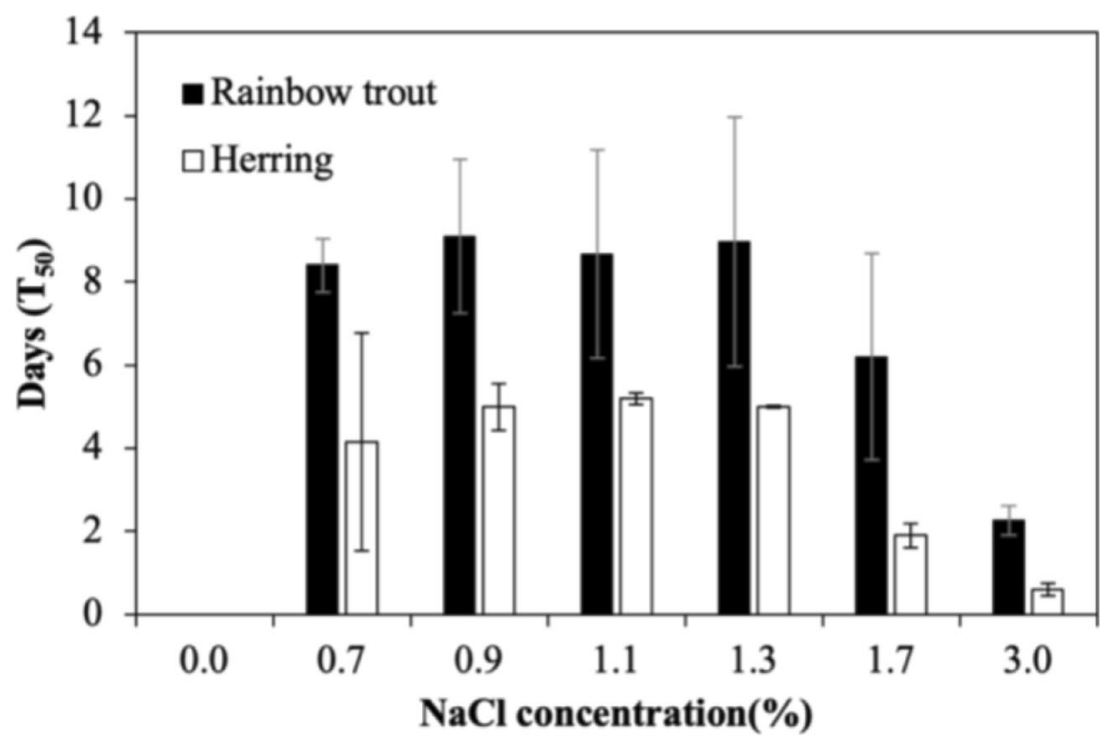

Osmotic fragility of trout and herring wr-RBCs was further investigated to specify the optimal salinity range causing minimal hemolysis. Figure 2 shows the number of days required for the sample to reach $\mathrm{T}_{50}$. Herring wr-RBCs in the salinity range 0.9 $1.3 \%(154-222 \mathrm{mM}) \mathrm{NaCl}$ have a significantly longer stability $(p<0.05)$ compared with incubation in both $0 \%$ and $3 \%(513$ $\mathrm{mM}) \mathrm{NaCl}$, whereas trout wr-RBC stability is significantly longer $(p<0.05)$ when incubated within the salinity range $0.7-1.3 \%$ (120-222 $\mathrm{mM}) \mathrm{NaCl}$, compared with incubation in $0 \%$ or $3 \%$ (513 mM) NaCl. Overall, herring wr-RBCs were more fragile compared with trout, within the studied salinity range.

Multivariate analysis using data from a Box-Behnken design was performed to elucidate the nature of the relation between (i) temperature, salinity, and mechanical stress and (ii) hemolysis at different time points. The design also allowed investigation of interaction effects; however, no significant interaction effect was found. Investigating the association between temperature and hemolysis, a weak linear term was found at day 7 (Fig. 3a). The association between temperature and hemolysis increased over time and at time points 11 and 13 days (Fig $3 \mathrm{~b}$ and c, respectively) both a strong linear and quadratic term was found, with a minimum for hemolysis at $2.5^{\circ} \mathrm{C}$. Therefore, in further experiments (see Effect of Blood Plasma Components and Potential Causes for Storage-Induced Hemolysis - metHb, $\mathrm{KCl}$ Leakage, and Bacterial growth), samples were kept in a cold room at $3 \pm 1{ }^{\circ} \mathrm{C}$. A strong linear association was found between mechanical stress and hemolysis right after mechanical stress was applied (Fig. 3d). This association decreased with time but could also be seen at time points 3 and 5 days (Fig. 3e and f, respectively). Within the chosen range of salinity in the multivariate analysis $0.7-1.0 \%$ (120-171 $\mathrm{mM}) \mathrm{NaCl}$, no significant association with hemolysis was found.

\section{Effect of Blood Plasma Components}

WB suspended in $0.9 \%(154 \mathrm{mM}) \mathrm{NaCl}$ were up to three times more stable towards hemolysis in comparison with wr-RBCs in the same salinity (Fig. 4). To better understand the protecting effect of plasma, the effect of energy-providing compounds and antioxidants found in plasma was investigated. Glucose was measured to $6.0 \pm 0.4$ and $6.0 \pm 0.3 \mathrm{mM}(n=1, r=3)$ in trout and herring blood plasma, respectively. Glucose $(6 \mathrm{mM})$ added to wr-RBCs in $0.9 \%(154 \mathrm{mM}) \mathrm{NaCl}$ had a varying effect on hemolysis ranging from no effect up to 18 days prolongation of $\mathrm{T}_{50}(n=6, r=2)$. In herring, saline with $6 \mathrm{mM}$ glucose resulted only in a slight extension of $\mathrm{T}_{50}$ (Fig. 4) with up to 1 day $(n=2, r$ $=2$ ). The addition of 10 and $20 \mathrm{mM}$ of glucose to the trout wrRBCs did not provide increased stability compared with $6 \mathrm{mM}$ glucose. The effect of adding adenosine triphosphate (ATP) (30 or $100 \mu \mathrm{M})$ to the $0.9 \%(154 \mathrm{mM}) \mathrm{NaCl}$, reduced $\mathrm{T}_{50}$ with 1.5 and 3 days, respectively $(n=2, r=2)$; the stability decreased with increasing ATP concentration (data not shown). The ascorbic acid concentration in trout and herring blood plasma was measured to $169.8 \pm 19.9 \mu \mathrm{M}$ and $109.6 \pm 26.7 \mu \mathrm{M}(\mathrm{n}=2, \mathrm{r}=3)$, respectively. Adding ascorbic acid to the $0.9 \%(154 \mathrm{mM}) \mathrm{NaCl}$ to a final concentration of $200 \mu \mathrm{M}$ increased the $\mathrm{T}_{50}$ with 5-11 days in trout wr-RBCs $(n=3, r=3)$. However, the effect of this concentration of ascorbic acid on herring wr-RBCs resulted in non-systematic effects, from a 2.5 days increase of $\mathrm{T}_{50}$ down to a decrease with 2.3 days (Fig. 4). Comparing trout and herring wr$\mathrm{RBCs}$ when stored in plasma or $0.9 \%(154 \mathrm{mM}) \mathrm{NaCl}$ with added glucose or ascorbic acid, it was noted that herring wrRBCs had shorter stability. Blood plasma resulted in 20.5 and 14.7 days longer $T_{50}$ of trout and herring wr-RBCs respectively. Blood plasma was also significantly better at maintaining wrRBC stability compared with any of the other added substances (Fig. 4). 

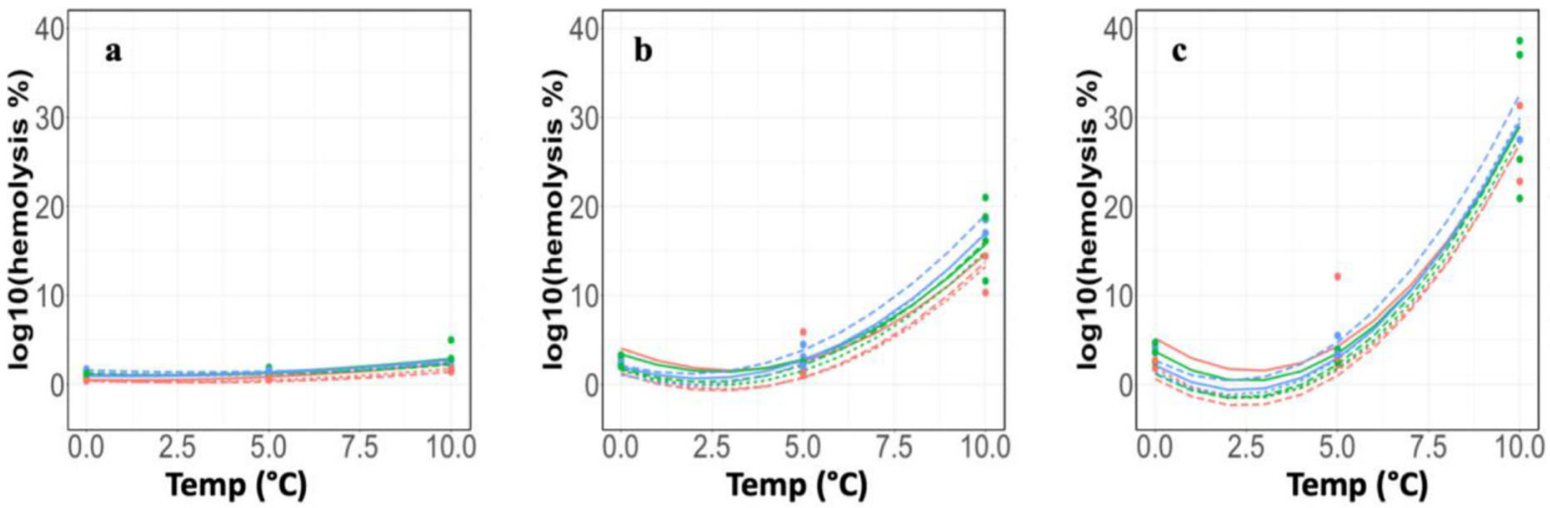

$\mathrm{NaCl}(\%)$

$-0.7$

…... 0.85

$--1.0$

Temp ( $\left.{ }^{\circ} \mathrm{C}\right)$

$\rightarrow 0$

$\rightarrow 10$

$\rightarrow 5$
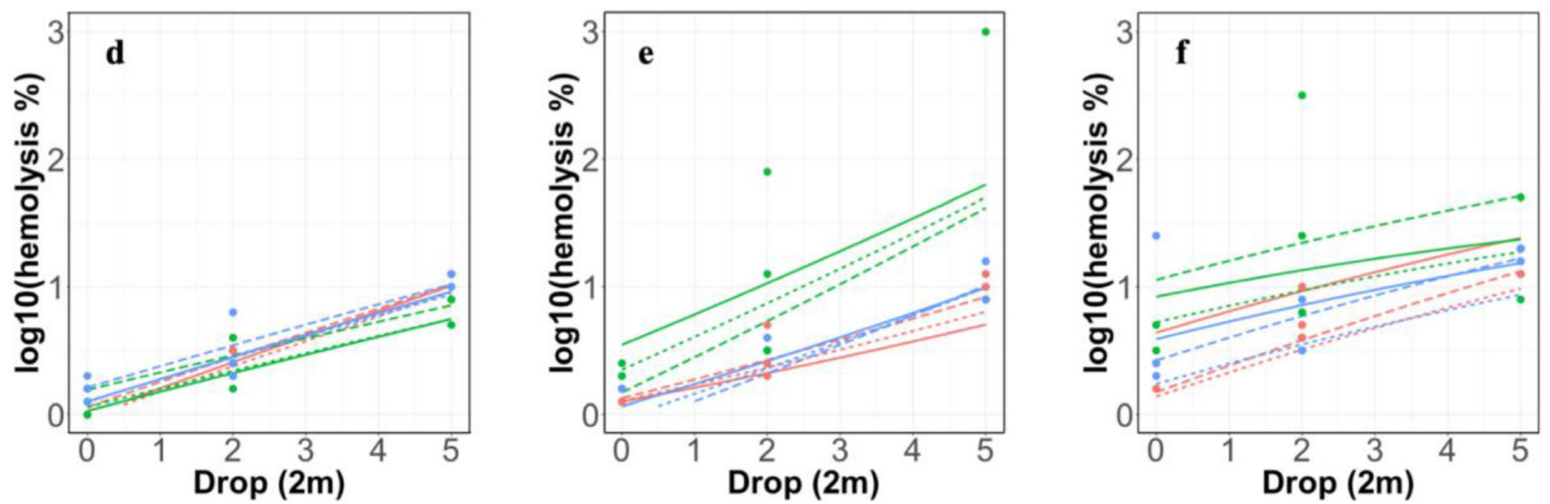

$\mathrm{NaCl}(\%)$

$-0.7$

....... 0.85

- 1.0

Drop (2m)

$\because 0$

$\rightarrow 2$

$\rightarrow-5$

Fig. 3 Association between temperature at time point 7, 11 and 13 days $(\mathbf{a}-\mathbf{c})$ and mechanical impact at time point $0.5 \mathrm{~h}, 3$ days and 5 days $(\mathbf{d}-\mathbf{f})$ with hemolysis of trout wr-RBCs, as revealed when evaluating the Box-Behnken design

\section{Potential Causes for Storage-Induced Hemolysis-metHb, KCl Leakage, and Bacterial Growth}

The cause of the sudden hemolysis seen during storage of wrRBCs was investigated, with one theory being that released $\mathrm{Hb}$ oxidized to metHb, thus causing an external oxidative attack on the membrane of still intact wr-RBCs. Adding 10 $\mathrm{g} / \mathrm{L}$ metHb to the $0.9 \%(154 \mathrm{mM}) \mathrm{NaCl}$ saline unexpectedly increased $\mathrm{T}_{50}$ with 5 days of the trout wr-RBCs (Fig. 5a). To investigate the effect of a globular protein per se on the stability of RBCs, 5,10 , and $20 \mathrm{~g} / \mathrm{L}$ bovine serum albumin (BSA) was added to $0.9 \%(154 \mathrm{mM}) \mathrm{NaCl}$. The same stabilizing effect that was provided by metHb was found with the addition of these concentrations of BSA, i.e., an increase of $\mathrm{T}_{50}$ with around 5 days (Fig. 5b). Another theory was that $\mathrm{KCl}$ was released into the storage solution after hemolysis, which could cause further hemolysis of still intact RBCs. Therefore, $0.9 \%(154 \mathrm{mM}) \mathrm{NaCl}$ was replaced with $0.9 \%(154 \mathrm{mM}) \mathrm{KCl}$ or with $0.45 \%(77 \mathrm{mM}) \mathrm{KCl}$ plus $0.45 \%(77 \mathrm{mM}) \mathrm{NaCl}$.
Fig. 4 Number of days passing until trout and herring wr-RBCs in their own plasma or in $0.9 \%$ (154 mM) $\mathrm{NaCl}$ with added glucose or ascorbic acid reached $50 \%$ hemolysis $\left(\mathrm{T}_{50}\right)$. Data represent mean values \pm SD. Experimental replicates for the trout wr-RBCs were as follows: $0.9 \%(154 \mathrm{mM})$ $\mathrm{NaCl}(n=9) ; 6 \mathrm{mM}$ glucose $(n=$ 6); $30 \mu \mathrm{M}$ and $200 \mu \mathrm{M}$ ascorbic acid $(n=3)$; blood plasma $(n=2)$, with the measurement being replicated twice $(r=2)$. For herring RBCs, $n=2$ and $r=2$

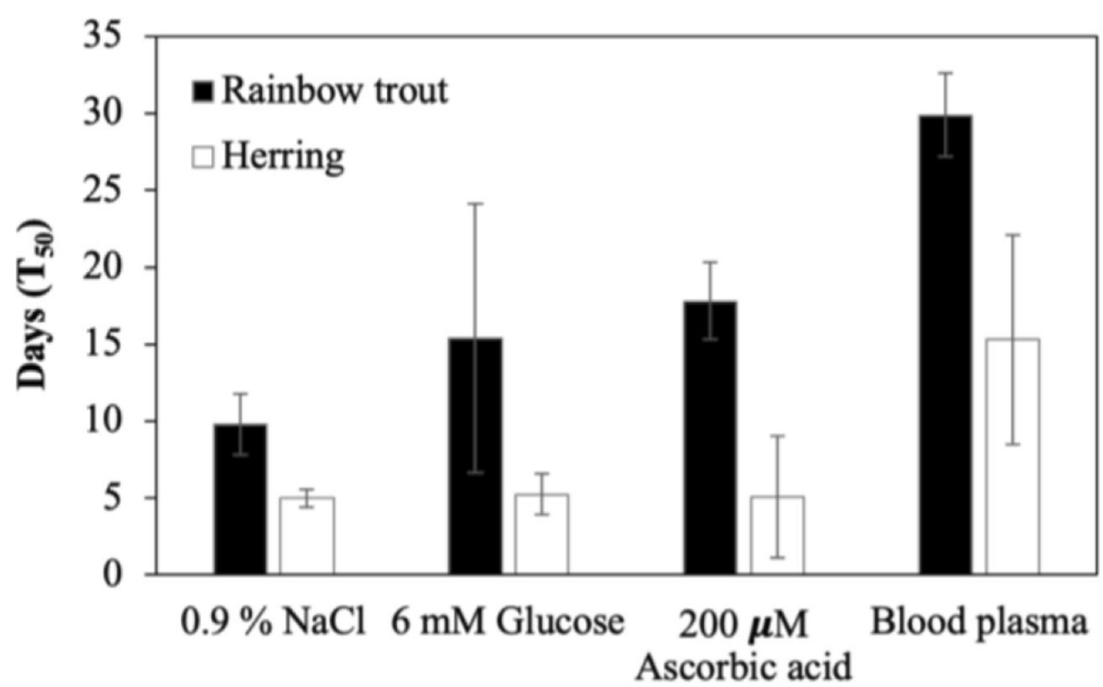




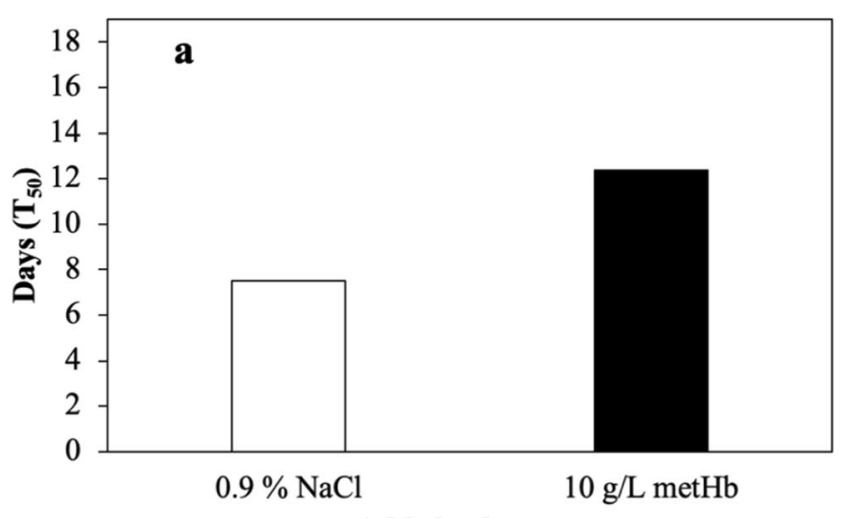

Added substance

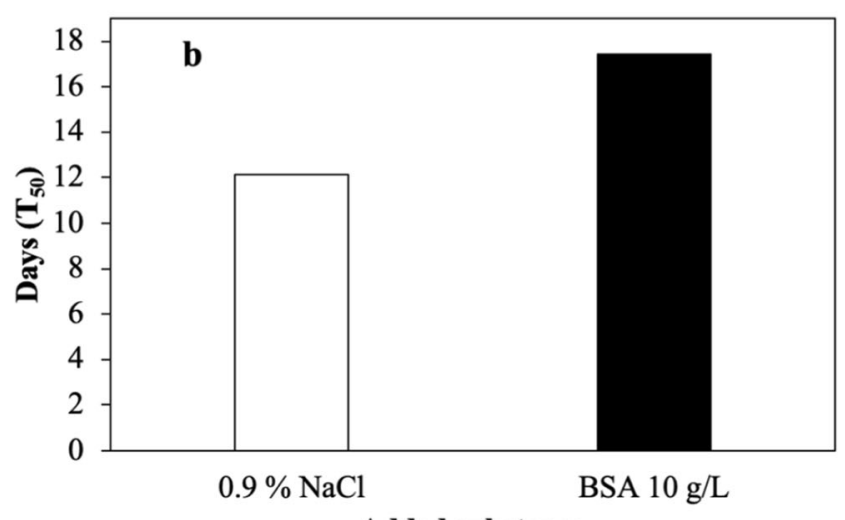

Added substance

Fig. 5 Effect of $10 \mathrm{~g} / \mathrm{L}$ metHb (graph a) or BSA (graph b) in $0.9 \%$ (154 $\mathrm{mM}) \mathrm{NaCl}$ on days needed to reach $50 \%$ hemolysis - $\left(\mathrm{T}_{50}\right)$ in the trout wr$\operatorname{RBCs}(n=1, r=2)$

However, no change in stability of trout wr-RBCs was noted from this change in salt (data not shown). Streptomycin/PEST $(100 \mu \mathrm{g} / \mathrm{mL})$ in $0.9 \%(154 \mathrm{mM}) \mathrm{NaCl}$ was finally tested as broad range antibiotics to investigate whether microbial growth could be the cause of the sudden hemolysis. The antibiotics resulted in a slight increase of $\mathrm{T}_{50}$ with 2.6 days, in trout wr-RBCs (data not shown in graph).

\section{Discussion}

As a tentative new approach to minimize $\mathrm{Hb}$-mediated lipid oxidation in herring and other fish species, this study for the first time investigated how a selection of chemical and physical parameters, typically varying during early handling of fish, affected the stability of RBCs. This knowledge can thus be used to minimize $\mathrm{Hb}$ contamination of the fish muscle, which would be of particular interest for small pelagic fish species such as herring which are not commercially bleed after capture. However, this strategy would also be of interest in bled fish species, as less than $50 \%$ of the blood is eliminated from bleeding (Olsen et al. 2014).

\section{Osmotic Fragility and Species Variation}

The rapid hemolysis seen when RBCs were in contact with hypo- or hypertonic solutions (Fig. $1 \mathrm{a}$ and b) reveals that the conditions used in, e.g., RSW tanks and in the filleting process, respectively, are highly critical for the RBC stability. Highest stability of the RBCs of both species was found with salinities close to the physiological, 0.9-1.3\% (154-222 mM) which indeed is in agreement with the general behavior of cells under varying salinity conditions (Ayik 2009; Ezell et al. 1969; Frei and Perk 1964; Khan et al. 1972; Schmidtnielsen 1974; Singh et al. 2019). Optimizing the salinity of storing and rinsing solutions used in processing could thus be a particularly beneficial strategy to avoid oxidation in muscle from small active and blood-rich fish species, such as herring, which are not commercially bled. The fact that muscles in these species are highly capillarized (Greerwalker and Pull 1975; Shewfelt 1981), and thus very rich in Hb, could explain their high susceptibility to lipid oxidation (Richards and Hultin 2002; Undeland et al. 2003).

Despite the ability of fish to regulate the osmolality of their body fluids (Schmidtnielsen 1974), some batch and species variation in osmotic fragility was noted when wr-RBCs were stored in solutions with varying salinity (Fig. 2). The batch variations could be linked to factors such as diseases, hormones, and access to feed (Fänge 1992; Kiron et al. 1994), whereas species variation could be linked to stress during capture. The blood from herring, which was bled immediately after capture from the sea, had a higher osmolality in its plasma compared with trout. The higher osmolality could be caused by stress during the capture of the herring, causing the gills to open to ensure maximal oxygen uptake. The increased diffusion area in the gills in turn causes osmotic problems, showing up as raised plasma osmolality (Sardella and Brauner 2006). Furthermore, the species variation in hemolysis could also reflect differences in the antioxidant systems of trout and herring blood, similar to the difference found in the antioxidant system between the muscle (R. Li et al. 2005; Passi et al. 2002; Undeland et al. 2003) or the blood (Perez et al. 2019; Rudneva 1997; Stagsted and Young 2002) from different animal species, including fish.

\section{The Effect of Temperature}

In the early steps of the process chain, whole fish is stored under cold conditions either in boxes with ice (normally 1:3 fish to ice ratio) or in RSW (Stroud 2001). Generally, reduced temperature implies reduced metabolism of cells, reduced bacterial growth, and reduced enzymatic activity, thus maintaining fish quality (Huss 1995). The specific relation between process temperature and stability of fish RBCs has not previously been reported. In our study, less hemolysis was found at 0-6 ${ }^{\circ} \mathrm{C}$, with a minimum at $2.5^{\circ} \mathrm{C}$ (Fig. $3 \mathrm{a}-\mathrm{c}$ ), which is in 
agreement with the results of (Blaine et al. 2019), who found that storage at $2{ }^{\circ} \mathrm{C}$ give better viability of human RBCs which they ascribed reduced RBC metabolism, such as slower $\mathrm{pH}$ drop due to slower formation of lactate. Furthermore, the FDA-approved storage temperature of human RBCs is at 1$6{ }^{\circ} \mathrm{C}$ (FDA 2018).

\section{The Effect of Mechanical Stress}

In several steps of the fish processing chain, the risk of inducing mechanical stress on the RBCs can be identified. The negative quality effect from crowding and pumping has previously been ascribes as a possible cause for, e.g., blood spotting in fish muscle (S. H. Olsen et al. 2006; Roth et al. 2005). Studying the impact of mechanical stress on trout wr-RBCs, we found a linear relation between hemolysis and mechanical stress (Fig. 3 d-f). Hemolysis was highest in close connection to the event of mechanical stress, meaning that wr-RBCs injured by the mechanic stress hemolyze in proximity to the event, whereas some wr-RBCs are completely unaffected by the stress event. In order to rule out eventual effects of damage to the wr-RBCs during the washing procedure (see Preparation of Washed Resuspended Red Blood Cells), washed RBCs was resuspended in blood plasma and stored while hemolysis was measured over time. No stability difference could be found compared with WB.

\section{Protecting Blood Plasma Components}

Interestingly, all experiments performed on WB showed longer RBC stability compared with the same treatment on wrRBCs. These findings suggest that there are components in blood plasma which protect the RBCs from hemolysis. Similar effects of plasma were also identified by Richards and Hultin (2002), in which they found that limiting hemolysis delayed lipid oxidation in washed cod muscle and that blood plasma delayed the lipid oxidation. Blood plasma is well known for high levels of antioxidants such as ascorbic acid, uric acid, tocopherol, and organic molecules such as various proteins (Wayner et al. 1987). Since oxidation of the cell membrane lipids can cause lysis (Fukunaga et al. 1999), antioxidants could have a preventive effect. This was partly confirmed when 50,100 , or $200 \mathrm{mM}$ ascorbic acid was added to wr-RBCs. This is around the endogenous level found in trout $(169.8 \pm 19.9 \mu \mathrm{M})$ and herring $(109.6 \pm 26.7 \mu \mathrm{M})$. The antioxidative and radical scavenging activity of ascorbic acid is well known, and ascorbic acid has previously been identified as an outstanding antioxidant in human blood (Frei et al. 1989). However, in all experiments, WB was still more stable than wr-RBCs in saline with added ascorbic acid. The unattainable protection provided by blood plasma may thus be due to the cooperative activity of antioxidants and compounds protecting the RBCs according to other mechanisms (Frei et al. 1989). One such candidate could be glucose, which is widely used in different RBC storing solutions, such as SAG$\mathrm{M}$ to maintain the metabolism of the RBCs (Hess and Greenwalt 2002). The addition of glucose around and above the endogenous levels to blood plasma $(2,6,10$, or $20 \mathrm{mM})$ indeed increased the stability of wr-RBCs, which was more pronounced for trout wr-RBCs compared with herring wrRBCs. The latter could be due to species differences in the permeability of glucose to RBCs (Fänge 1992). In a study performed on amphibian blood increased metabolism, thus higher ATP levels, decreased the osmotic fragility of RBCs (Goniakow 1974). Similarly, other studies have shown that increased metabolism and ATP production in the RBC prevent intracellular potassium loss (Whittam 1968). However, adding extracellular ATP as an additional protective candidate of plasma surprisingly decreased the wr-RBC stability, more so with increasing ATP concentration (100 vs. $30 \mu \mathrm{M}$ ATP). The cytotoxicity of ATP has previously been seen in human cervical cancer cells (Mello et al. 2014).

\section{Potential Reasons for the Exponential Lysis}

Implying that oxidation of lipids in the RBC membrane is a contributing reason to hemolysis also implies that prooxidants could induce hemolysis. MetHb is a highly oxidative form of the $\mathrm{Hb}$ molecule and compared with mammalian $\mathrm{Hb}$, fish $\mathrm{Hb}$ undergo rapid autooxidation (Aranda et al. 2009). During metHb formation, superoxide-anion radicals are formed which can induce lipid peroxidation of the fish RBC membrane (Kawatsu et al. 1991; Soldatov and Parfenova 2001). One of our initial hypotheses to explain the exponential behavior of the observed hemolysis (Fig. 1) was that it involved an oxidative attack from $\mathrm{Hb}$ molecules that had leaked out from the RBCs and been oxidized to metHb, thus a sort of "self-attack". This phenomenon has been seen when exposing RBCs to ozone, causing oxidation of RBCs and the formation of metHb, due to $\mathrm{Hb}$-derived reactive oxygen species (Fukunaga et al. 1999). In our experiments, an increasing metHb concentration was observed in the samples over 1week storage time (data not shown). However, incubating wr-RBCs with metHb surprisingly increased the stability towards hemolysis (Fig. 5a), possibly due to increased colloidal osmotic pressure (COP) of the external solution, which would decrease the transmembrane difference in COP and thereby stabilize the wr-RBCs (Kure and Sakai 2017). This hypothesis was confirmed by adding another globular protein, bovine serum albumin (BSA), at the same concentration (Fig. 5b). Results in this direction have also been noted by previous researchers (Sumpelmann et al. 2000; Hughes et al. 1986). Exposing a suspension of human RBCs in a gelatin and albumin fluid, instead of $0.9 \%(154 \mathrm{mM}) \mathrm{NaCl}$, to mechanical stress, showed increased stability of the RBCs (Sumpelmann et al. 2000). Another theory explored to explain the 
exponential behavior of hemolysis which was noted in all trials was that extracellular $\mathrm{KCl}$ would gradually accumulate by hemolysis of RBCs and then stimulate further sudden lysis. However, fully or partly replacing $0.9 \%(154 \mathrm{mM}) \mathrm{NaCl}$ by $\mathrm{KCl}$ showed similar results, implying that the electrolyte can be exchanged as long as the external and internal electrolyte concentrations are in equilibrium. These results are in accordance with previous studies performed on human RBCs (Nepal and Rao 2011). This could be of importance in the development of novel storage solutions for fish, targeting maximal RBC stability.

\section{Conclusion}

Overall, the results of this study indicate the possibility to significantly improve the stability of RBCs with few adjustments in a conventional fish processing chain. Cold temperature $0-6{ }^{\circ} \mathrm{C}$, with a minimum at $2.5^{\circ} \mathrm{C}$, and minimal mechanical impact turned out to be highly important factors. Furthermore, the osmolarity (salinity) of the process water should be adapted to the osmolarity of the blood, rather than utilizing seawater or tap water in pure form. The highest stability of the RBCs was obtained when incubated in blood plasma or in $0.9 \%(154 \mathrm{mM}) \mathrm{NaCl}$ and adding components endogenous to plasma, $6 \mathrm{mM}$ glucose, or $200 \mu \mathrm{M}$ ascorbic acid. Further investigations in whole fish muscle and bloodenriched fish muscle model systems are however necessary to investigate how post-mortem fish quality in a broader perspective will be affected by increased RBC stability, as a result of new fish handling protocols. For example, it should be ensured that, e.g., a change in salinity of the process water or use of additives does not give negative effect on the flavor of the fish muscle or harm the cooling capacity of RSW tanks.

\begin{abstract}
Acknowledgement The authors acknowledge Dr. Rikard Fristedt for his support in blood plasma ascorbic acid determination and Diana Sanchez Caicedo for her support with the statistical analysis (Chalmers University of Technology). Thanks are also due to Dr. James Hinchliffe for his assistance with bleeding trout and Dr. Jonathan Roques for his support with glucose measurements (Gothenburg University). The authors would also like to acknowledge MD. Birgitta Swolin for fruitful discussions regarding blood.
\end{abstract}

Funding Information Open access funding provided by Chalmers University of Technology. This work was supported by the Swedish research council for sustainable development (FORMAS) grant nos. 187850/1 and 2016-0118.

Compliance with Ethical Standards The bleeding of trout and herring was approved by the regional animal ethics committee in Gothenburg, permit number 167-2013.

Open Access This article is licensed under a Creative Commons Attribution 4.0 International License, which permits use, sharing, adaptation, distribution and reproduction in any medium or format, as long as you give appropriate credit to the original author(s) and the source, provide a link to the Creative Commons licence, and indicate if changes were made. The images or other third party material in this article are included in the article's Creative Commons licence, unless indicated otherwise in a credit line to the material. If material is not included in the article's Creative Commons licence and your intended use is not permitted by statutory regulation or exceeds the permitted use, you will need to obtain permission directly from the copyright holder. To view a copy of this licence, visit http://creativecommons.org/licenses/by/4.0/.

\section{References}

Aranda, R., Cai, H., Worley, C. E., Levin, E. J., Li, R., Olson, J. S., ... Richards, M. P. (2009). Structural analysis of fish versus mammalian hemoglobins: Effect of the heme pocket environment on autooxidation and hemin loss. Proteins-Structure Function and Bioinformatics, 75(1), 217-230. doi:https://doi.org/10.1002/prot. 22236

Ayik, S. B. A. O. (2009). Hematological parameters and erythrocyte osmotic fragility in rainbow trout, Oncorhynchus mykiss, experimentally infected with Pseudomonas putida. Journal of Fisheries and Aquatic Science, 4(5), 246-253.

Babakhani, A., Farvin, K. H. S., \& Jacobsen, C. (2016). Antioxidative effect of seaweed extracts in chilled storage of minced Atlantic mackerel (Scomber scombrus): Effect on lipid and protein oxidation. Food and Bioprocess Technology, 9(2), 352-364. https://doi. org/10.1007/s11947-015-1630-9.

Benesch, R., Macduff, G., \& Benesch, R. E. (1964). Spectra of deoxygenated hemoglobin in Soret region. Science, 144(361), 68. https:// doi.org/10.1126/science.144.3614.68.

Blaine, K. P., Cortes-Puch, I., Sun, J. F., Wang, D., Solomon, S. B., Feng, J., ... Natanson, C. (2019). Impact of different standard red blood cell storage temperatures on human and canine RBC hemolysis and chromium survival. Transfusion, 59(1), 347-358. doi:https://doi.org/ 10.1111/trf.14997

Cavonius, L. R., \& Undeland, I. (2017). Glazing herring (Clupea harengus) fillets with herring muscle press juice: Effect on lipid oxidation development during frozen storage. International Journal of Food Science and Technology, 52(5), 1229-1237. https://doi.org/10.1111/ijfs.13399.

Ezell, G. H., Sulya, L. L., \& Dodgen, C. L. (1969). Osmotic fragility of some fish erythrocytes in hyptotonic saline. Comparative Biochemistry and Physiology, 28(1), 409. https://doi.org/10.1016/ 0010-406x(69)91354-1.

Fänge, R. (1992). Fish blood cells. In Fish physiology, the cardiovascular system (pp. 1-54): Elsevier.

FDA. (2018). Additional standards for human blood and blood products - CFR640.4. Retrieved from https://www.accessdata.fda.gov/ scripts/cdrh/cfdocs/cfcfr/CFRSearch.cfm?fr=640.4.

Frei, Y. F., \& Perk, K. (1964). Osmotic hemolysis of nucleated erythrocytes. Experimental Cell Research, 35(2), 230-238. https://doi.org/ 10.1016/0014-4827(64)90090-4.

Frei, B., England, L., \& Ames, B. N. (1989). Ascorbate is an outstanding antioxidant in human-blood plasma. Proceedings of the National Academy of Sciences of the United States of America, 86(16), 6377-6381. https://doi.org/10.1073/pnas.86.16.6377.

Fukunaga, K., Nakazono, N., Suzuki, T., \& Takama, K. (1999). Mechanism of oxidative damage to fish red blood cells by ozone. Iubmb Life, 48(6), 631-634. doi:Doi. https://doi.org/10.1080/ 713803566.

Fyhn, U. E. H., Fyhn, H. J., Davis, B. J., Powers, D. A., Fink, W. L., \& Garlick, R. L. (1979). Hemoglobin heterogeneity in Amazonian 
fishes. Comparative Biochemistry and Physiology Part A: Physiology, 62(1), 39-66. https://doi.org/10.1016/0300-9629(79) 90740-0.

Goniakow L. (1974). Glucose-depending increase in erythrocyte metabolism correlated with greater resistance to hypotonic solutions. Bulletin De L Academie Polonaise Des Sciences-Serie Des Sciences Biologiques, 22(2), 101-104. Retrieved from $<$ Go to ISI>://WOS:A1974S790300007

Grahm, M. J., Johnston, W. A., \& Nicholson, F. J. (1992). Ice in fisheries. Greerwalker, M., \& Pull, G. A. (1975). Survey of red and white muscle in marine fish. Journal of Fish Biology, 7(3), 295-300. https://doi.org/ 10.1111/j.1095-8649.1975.tb04602.x.

Hess, J. R., \& Greenwalt, T. G. (2002). Storage of red blood cells: New approaches. Transfusion Medicine Reviews, 16(4), 283-295. https:// doi.org/10.1053/tmrv.2002.35213.

Hughes, G. M., Kikuchi, Y., \& Barrington, J. (1986). Physiological salines and the mechanical properties of trout red blood cells. Journal of Fish Biology, 29(3), 393-402. https://doi.org/10.1111/j.10958649.1986.tb04955.x.

Huss, H. H. (1995). Quality and quality changes in fresh fish.

Kawatsu, H., Yamazaki, T., \& Miyamori, E. (1991). In vitro hemolysis and methemoglobin formation in common carp erythrocytes induced by hydrogen peroxide and hypoxanthine-xanthine oxidase. Nippon Suisan Gakkaishi, 57(12), 2299-2305. https://doi.org/10. 2331/suisan.57.2299.

Khan, S. H., Siddiqui, A. Q., \& Hasnain, A. (1972). The hypotonic fragility of some fish erythrocytes. Proceedings of the Indian Academy of Sciences - Section B, 75(6), 266-270. https://doi.org/ 10.1007/BF03045720.

Kiron, V., Takeuchi, T., \& Watanabe, T. (1994). The osmotic fragility of erythrocytes in rainbow trout under different dietary fatty acid status. Fisheries Science, 60(1), 93-95. https://doi.org/10.2331/fishsci.60. 93.

Kuhlin, M. (2019). [Temperatures in the primary processing at Scandic Pelagic AB (personal communication)].

Kure, T., \& Sakai, H. (2017). Transmembrane difference in colloid osmotic pressure affects the lipid membrane fluidity of liposomes encapsulating a concentrated protein solution. Langmuir, 33(6), 15331540. https://doi.org/10.1021/acs.langmuir.6b04643.

Larsson, K. J., \& Undeland, I. K. (2010). Effect of caffeic acid on haemoglobin-mediated lipid and protein oxidation in washed cod mince during ice and frozen storage. Journal of the Science of Food and Agriculture, 90(14), 2531-2540. https://doi.org/10.1002/ jsfa. 4121

Larsson, K., Almgren, A., \& Undeland, I. (2007). Hemoglobin-mediated lipid oxidation and compositional characteristics of washed fish mince model systems made from cod (Gadus morhua), herring (Clupea harengus), and salmon (Salmo salar) muscle. Journal of Agricultural and Food Chemistry, 55(22), 9027-9035. https://doi. org $/ 10.1021 / \mathrm{jf070522z.}$

Lee, S. K., Tatiyaborworntham, N., Grunwald, E. W., \& Richards, M. P. (2015). Myoglobin and haemoglobin-mediated lipid oxidation in washed muscle: Observations on crosslinking, ferryl formation, porphyrin degradation, and haemin loss rate. Food Chemistry, 167, 258-263. https://doi.org/10.1016/j.foodchem.2014.06.098.

Lewis, J. H., \& Ferguson, E. E. (1966). Osmotic fragility of premammalian erythrocytes. Comparative Biochemistry and Physiology, 18(3), 589-595. https://doi.org/10.1016/0010406X(66)90242-8.

Li, R., Richards, M. P., \& Undeland, I. (2005). Characterization of aqueous components in chicken breast muscle as inhibitors of hemoglobin-mediated lipid oxidation. Journal of Agricultural and Food Chemistry, 53(3), 767-775. https://doi.org/10.1021/ jf049515q.

Li, H., Zhou, X., Gao, P., Li, Q., Li, H., Huang, R., \& Wu, M. (2016). Inhibition of lipid oxidation in foods and feeds and hydroxyl radical- treated fish erythrocytes: A comparative study of Ginkgo biloba leaves extracts and synthetic antioxidants. Animal Nutrition, 2(3), 234-241. https://doi.org/10.1016/j.aninu.2016.04.007.

Lu, H., Luo, Y., \& Feng, L. (2014). Effects of hydrolysates from silver carp (Hypophthalmichthys molitrix) scales on rancidity stability and gel properties of fish products. Food and Bioprocess Technology, 7(8), 2178-2188. https://doi.org/10.1007/s11947-013-1196-3.

Lykkesfeldt, J. (2000). Determination of ascorbic acid and dehydroascorbic acid in biological samples by high-performance liquid chromatography using subtraction methods: Reliable reduction with tris[2-carboxyethyl] phosphine hydrochloride. Analytical Biochemistry, 282(1), 89-93. https://doi.org/10.1006/abio.2000. 4592.

Maqsood, S., \& Benjakul, S. (2011). Effect of bleeding on lipid oxidation and quality changes of Asian seabass (Lates calcarifer) muscle during iced storage. Food Chemistry, 124(2), 459-467. https://doi.org/ 10.1016/j.foodchem.2010.06.055

Maqsood, S., \& Benjakul, S. (2013). Effect of kiam (Cotylelobium lanceolatum Craib) wood extract on the haemoglobin-mediated lipid oxidation of washed Asian sea bass mince. Food and Bioprocess Technology, 6(1), 61-72. https://doi.org/10.1007/s11947-0110530-x.

Mello, P. D., Filippi-Chiela, E. C., Nascimento, J., Beckenkamp, A., Santana, D. B., Kipper, F., ... Buffon, A. (2014). Adenosine uptake is the major effector of extracellular ATP toxicity in human cervical cancer cells. Molecular Biology of the Cell, 25(19), 2905-2918. doi: https://doi.org/10.1091/mbc.E14-01-0042

Miranda, J. M., Trigo, M., Barros-Velazquez, J., \& Aubourg, S. P. (2018). Quality enhancement of chilled lean fish by previous active dipping in Bifurcaria bifurcata alga extract. Food and Bioprocess Technology, 11(9), 1662-1673. https://doi.org/10.1007/s11947018-2131-4.

Nepal, O., \& Rao, J. P. (2011). Haemolytic effects of hypo-osmotic salt solutions on human erythrocytes. Kathmandu University Medical Journal, 9(34), 35-39.

Olsen, S. H., Sorensen, N. K., Stormo, S. K., \& Elvevoll, E. O. (2006). Effect of slaughter methods on blood spotting and residual blood in fillets of Atlantic salmon (Salmo salar). Aquaculture, 258(1-4), 462469. https://doi.org/10.1016/j.aquaculture.2006.04.047.

Olsen, S. H., Joensen, S., Tobiassen, T., Heia, K., Akse, L., \& Nilsen, H. (2014). Quality consequences of bleeding fish after capture. Fisheries Research, 153, 103-107. https://doi.org/10.1016/j. fishres.2014.01.011.

Passi, S., Cataudella, S., Di Marco, P., De Simone, F., \& Rastrelli, L. (2002). Fatty acid composition and antioxidant levels in muscle tissue of different Mediterranean marine species of fish and shellfish. Journal of Agricultural and Food Chemistry, 50(25), 7314 7322. https://doi.org/10.1021/jf020451y.

Perez, D. M., Tatiyaborworntham, N., Sifri, M., \& Richards, M. P. (2019). Hemolysis, tocopherol, and lipid oxidation in erythrocytes and muscle tissue in chickens, ducks, and turkeys. Poultry Science, 98(1), 456-463. https://doi.org/10.3382/ps/pey329.

Richards, M. P., \& Hultin, H. O. (2002). Contributions of blood and blood components to lipid oxidation in fish muscle. Journal of Agricultural and Food Chemistry, 50(3), 555-564. https://doi.org/ 10.1021/jf010562h.

Roth, B., Torrissen, O. J., \& Slinde, E. (2005). The effect of slaughtering procedures on blood spotting in rainbow trout (Oncorhynchus mykiss) and Atlantic salmon (Salmo salar). Aquaculture, 250(3), 796-803. https://doi.org/10.1016/j.aquaculture.2005.03.010.

Roth, B., Obach, A., Hunter, D., Nortvedt, R., \& Oyarzun, F. (2009). Factors affecting residual blood and subsequent effect on bloodspotting in smoked Atlantic salmon fillets. Aquaculture, 297(1-4), 163-168. https://doi.org/10.1016/j.aquaculture.2009.09. 019. 
Rudneva, I. I. (1997). Blood antioxidant system of Black Sea elasmobranch and teleosts. Comparative Biochemistry and Physiology Part C: Pharmacology, Toxicology and Endocrinology, 118(2), 255260. https://doi.org/10.1016/S0742-8413(97)00111-4.

Sánchez-Alonso, I., Borderías, J., Larsson, K., \& Undeland, I. (2007). Inhibition of hemoglobin-mediated oxidation of regular and lipidfortified washed cod mince by a white grape dietary fiber. Journal of Agricultural and Food Chemistry, 55(13), 5299-5305. https://doi. org/10.1021/jf0702242.

Sardella, B. A., \& Brauner, C. J. (2006). The Osmo-respiratory compromise in fish: The effects of physiological state and the ennvironment. In M. N. Fernandes (Ed.), Fish respiration and environment (1st ed., pp. 147-165). Boca Raton: Taylor \& Francis Group.

Schmidtnielsen, B. (1974). Osmoregulation - Effect of salinity and heavymetals. Federation Proceedings, 33(10), 2137-2146 Retrieved from $<$ Go to ISI $>$ ://WOS:A1974U549700008.

Shewfelt, R. L. (1981). Fish muscle lipolysis - A review. Journal of Food Biochemistry, 5(2), 79-100. https://doi.org/10.1111/j.1745-4514. 1981.tb00663.x.

Singh, S., Ponnappan, N., Verma, A., \& Mittal, A. (2019). Osmotic tolerance of avian erythrocytes to complete hemolysis in solute free water. Scientific Reports, 9(1), 7976. https://doi.org/10.1038/ s41598-019-44487-7.

Soldatov, A. A., \& Parfenova, I. A. (2001). The methemoglobin blood level and stability of circulating erythrocytes of the rockfish Scorpaena porcus to osmotic shock under conditions of experimental hypoxia. Journal of Evolutionary Biochemistry and Physiology, 37(6), 622-625. https://doi.org/10.1023/A:1014470311122.

Stagsted, J., \& Young, J. F. (2002). Large differences in erythrocyte stability between species reflect different antioxidative defense mechanisms. Free Radical Research, 36(7), 779-789. https://doi. org/10.1080/10715760290032638.

Stroud, G. D. (2001). The herring.

Sumpelmann, R., Schurholz, T., Marx, C., \& Zander, R. (2000). Protective effects of plasma replacement fluids on erythrocytes exposed to mechanical stress. Anaesthesia, 55(10), 976-979. https:// doi.org/10.1046/j.1365-2044.2000.01531.x.

Team, R. C (2019). A language and environment for statistical computing. Retrieved from https://www.R-project.org/.

Undeland, I., \& Lingnert, H. (1999). Lipid oxidation in fillets of herring (Clupea harengus) during frozen storage. Influence of prefreezing storage. Journal of Agricultural and Food Chemistry, 47(5), 20752081. https://doi.org/10.1021/j9980944w.

Undeland, I., Hultin, H. O., \& Richards, M. P. (2003). Aqueous extracts from some muscles inhibit hemoglobin-mediated oxidation of cod muscle membrane lipids. Journal of Agricultural and Food Chemistry, 51(10), 3111-3119. https://doi.org/10.1021/jf020770p.

Undeland, I., Kristinsson, H. G., \& Hultin, H. O. (2004). Hemoglobinmediated oxidation of washed minced cod muscle phospholipids: Effect of $\mathrm{pH}$ and hemoglobin source. Journal of Agricultural and Food Chemistry, 52(14), 4444-4451. https://doi.org/10.1021/ jf030560s.

Vesper, S. J., \& Vesper, M. J. (2004). Possible role of fungal hemolysins in sick building syndrome. Advances in Applied Microbiology, 55, 191-213. https://doi.org/10.1016/S0065-2164(04)55007-4.

Wang, T., Jónsdóttir, R., Kristinsson, H. G., Thorkelsson, G., Jacobsen, C., Hamaguchi, P. Y., \& Ólafsdóttir, G. (2010). Inhibition of haemoglobin-mediated lipid oxidation in washed cod muscle and cod protein isolates by Fucus vesiculosus extract and fractions. Food Chemistry, 123(2), 321-330. https://doi.org/10.1016/j. foodchem.2010.04.038

Waymouth, C. (1970). Osmolality of mammalian blood and of media for culture of mammalian cells. In Vitro, 6(2), 109-127. https://doi.org/ 10.1007/BF02616113.

Wayner, D. D. M., Burton, G. W., Ingold, K. U., Barclay, L. R. C., \& Locke, S. J. (1987). The relative contributions of vitamin-E, urate, ascorbate and proteins to the total peroxyl radical-trapping antioxidant activity of human-blood plasma. Biochimica et Biophysica Acta, 924(3), 408-419. https://doi.org/10.1016/0304-4165(87) 90155-3.

Whittam, R. (1968). Control of membrane permeability to potassium in red blood cells. Nature, 219(5154), 610. https://doi.org/10.1038/ $219610 \mathrm{a} 0$.

Wu, H., Ghirmai, S., \& Undeland, I. (2020). Stabilization of herring (Clupea harengus) by-products against lipid oxidation by rinsing and incubation with antioxidant solutions. Food Chemistry, 126337, 126337. https://doi.org/10.1016/j.foodchem.2020.126337.

Publisher's Note Springer Nature remains neutral with regard to jurisdictional claims in published maps and institutional affiliations. 